\title{
A Failed Predation Attempt on a Rusty Treefrog, Hypsiboas boans (Anura: Hylidae), by an Olive Whipsnake, Chironius fuscus (Squamata: Colubridae), in Southeastern Peru
}

Cristina Arrivillaga and Anik Levac

Crees Foundation, Urbanización Mariscal Gamarra B-5, Zona 1, Cusco, Perú (cristinaarrivillaga@gmail.com)

$\mathrm{T}$ The Olive Whipsnake, Chironius fuscus (Linnaeus 1578), is a diurnally active, semi-arboreal colubrid with a broad distribution in primary and secondary forests throughout most of the Amazon Basin and the northern half of South America (Barlett and Barlett 2003). The diet of this species consists of a wide variety of vertebrate prey, a large proportion of which are terrestrial anurans in the family Leptodactylidae with only a few reports of it predating arboreal treefrogs in the family Hylidae (Pastana et al. 2013). The Rusty Treefrog, Hypsiboas boans (Linnaeus 1758), is a very large (SVL to 12.5 $\mathrm{cm}$; Barlett and Barlett, 2003) nocturnally active frog that is widely distributed throughout South America (La Marca et al. 2010). Previous reports have documented anti-predatory behaviors in this genus that include distress calls (Bogert 1960, 2014; Hödl and Gollmann 1986; Lima 2005; Rocha and Lopez-Baucells 2014), lung inflation (Azevedo-Ramos 1995), thanatosis or death feigning, odor production, and open-arm displays (Angulo et al. 2007). Herein we report a predation attempt on $H$. boans by $C$. fuscus, with additional information on defensive behavior of $H$. boans.

At 1100 h on 5 April 2019, we encountered an adult Chironius fuscus attempting to consume an adult Hypsiboas

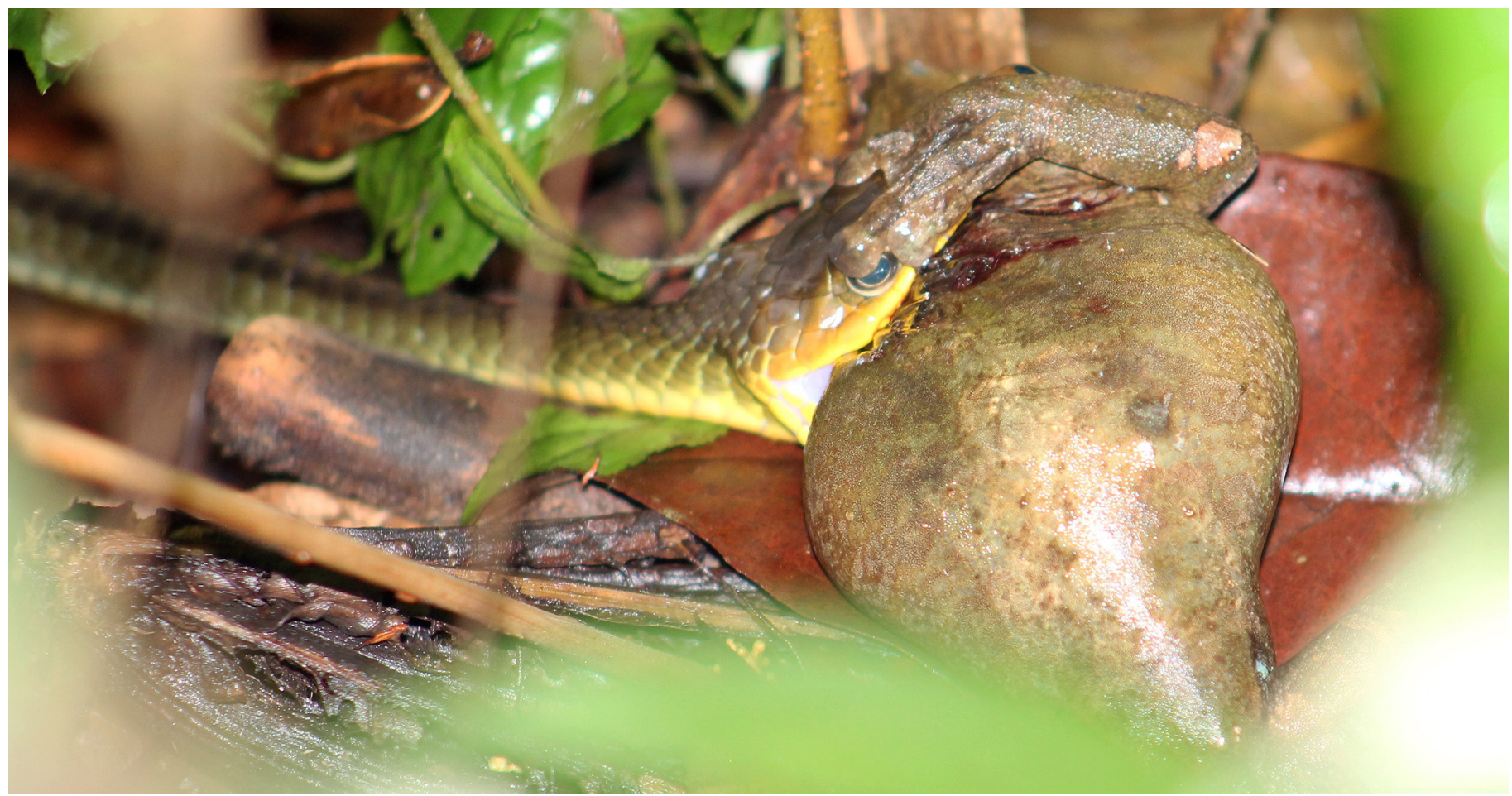

Fig. 1. An Olive Whipsnake (Chironius fuscus) attempting to consume an adult Rusty Treefrog (Hypsiboas boans). Note that the size of the frog is larger than normal due to inflating its lungs in an effort to avoid predation. Photograph by Anik Levac. 
boans (estimated SVL $=110 \mathrm{~mm}$ ) (Fig. 1). A distress call emitted by the frog enabled us to locate the event. The snake had the anterior half of the frog in its mouth, with the latter appearing to inflate its body. This behavior has been reported in several anurans, including one species in the genus Hypsiboas (Azevedo-Ramos 1995) but had not been reported previously for this species (Toledo et al. 2011). When encountered, the frog was jumping while emitting the distress call and inflating its body. After $1 \mathrm{~min} 40 \mathrm{sec}$ of observation, the frog managed to escape. The snake immediately fled into surrounding vegetation while the frog jumped $3 \mathrm{~m}$ away into a ditch. Further inspection revealed that the frog had severe lacerations on its anterior ventral region and torn skin on its left forearm (Fig. 2).

This observation suggests that the wide array of defensive strategies of $H$. boans can be effective against predators. Rocha and López-Baucells (2014) reported a Rusty Treefrog escaping a predation attempt by a Brown-banded Watersnake (Helicops angulatus), during which the frog also employed several antipredatory behaviors that included distress calls and leaping. Inflation might be particularly effective in this species due to its already large size, rendering it much more difficult for many predators to subdue it. Large size also appears to be related to its ability to emit distress calls. Toledo and Hadded (2009) noted that defensive calls are usually emitted only by larger frogs and that the larger the individual, the

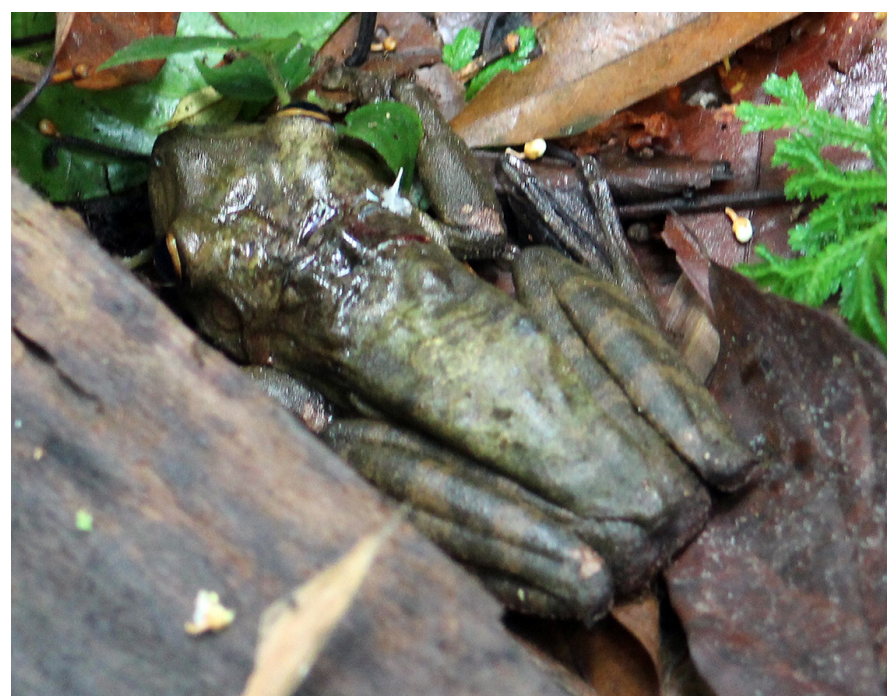

Fig. 2. an adult Rusty Treefrog (Hypsiboas boans) after fleeing the predation attempt. Note that the frog is no longer inflated and is back to its normal size. Wounds and lacerations can be seen behind the head, where the teeth of the $C$. fuscus were holding on to it minutes before. Photograph by Anik Levac. louder the call. Although vocalization likely is useful against predators with developed hearing, snakes are unlikely to be affected as they are believed to be unable to hear a distress call (Toledo and Haddad 2009). However, distress calls are known to attract mammalian and avian predators (Högstedt 1983), which might attempt predation on either the screaming victim, the initial predator, or both, thereby interrupting the predation attempt and providing an opportunity for the prey to flee (Höld and Gollmann 1986). The simultaneous use of several defensive strategies appears to increase the likelihood of a frog escaping from a predator (Toledo et al. 2011). This was evident in both this instance and in the observation reported by Azevedo-Ramos (1995).

\section{Acknowledgements}

We thank Juvenal Huari Castilla, the Manu Learning Center lodge manager, who first found the individuals and brought this predation attempt to our attention, and The Crees Foundation for providing the opportunity to conduct herpetological surveys at the Manu Learning Centre.

\section{Literature Cited}

Angulo, A., A.R. Acosta, and J.V. Rueda-Almonacid. 2007. Diversity and frequency of visual defensive behaviours in a population of Hypsiboas geographicus. Herpetological Journal 17: 138-140.

Azevedo-Ramos, C. 1995. Defense behaviors of the Neotropical treefrog Hyla geographica (Anura, Hylidae). Revista Brasileira de Biologia 55: 45-47.

Barlett, R.D. and P. Barlett. 2003. Reptiles and Amphibians of the Amazon: An Ecotourist's Guide. University Press of Florida, Gainesville, Florida.

Bogert, C.M. 1960. The influence of sound on the behavior of amphibians and reptiles, pp. 137-320. In: W.E. Lanyon and J.W. Tavolga (eds.), Animal Sounds and Communication. American Institute of Biological Sciences Publication No. 7. Intelligencer Printing Company, Washington, D.C.

Hödl, W. and G. Gollmann. 1986. Distress calls in Neotropical frogs. AmphibiaReptilia 7: 11-21.

Hogstedt, G. 1983. Adaptation unto death: Function of fear screams. The American Naturalist 121: 562-570.

La Marca, E., C. Azevedo-Ramos, L.A. Coloma, F. Solís, R. Ibáñez, C. Jaramillo, Q. Fuenmayor, S. Ron, and J. Hardy. 2010. Hypsiboas boans. The IUCN Red List of Threatened Species 2010: e.T55415A11304871. <http://dx.doi. org/10.2305/IUCN.UK.2010-2.RLTS.T55415A11304871.en>.

Lima, A.P., W.E Magnusson, M. Menin, L.K. Erdtmann, D.J. Rodrigues, C. Keller, and W. Hödl. 2005. Guide to the Frogs of Reserva Adolpho Ducke, Central Amazonia. Áttema Design Editorial, Manaus, Brazil.

Pastana, L., D. Mendes, and M. dos Santos-Costa. 2013. Diet, reproduction, and sexual dimorphism in the Vine Snake, Chironius fuscus (Serpentes: Colubridae), from Brazilian Amazonia. South American Journal of Herpetology 8: 168-174.

Rocha, R. and A. López-Baucells. 2014. Predation attempt of Hypsiboas boans (Anura: Hylidae) by Helicops angulatus (Squamata: Dipsadidae) with notes on defensive behavior. Alytes 30: 78-81.

Toledo, L.F. and C.F.B. Haddad. 2009. Defensive vocalizations of Neotropical anurans. South American Journal of Herpetology 4: 25-42.

Toledo, L.F., I. Sazima, and C.F.B. Haddad. 2011. Behavioural defences of anurans: an overview. Ethology Ecology \& Evolution 23:1-25. 